\title{
3.2 Evaluación del aprendizaje en Ciencias Básicas
}

Por Joel Zapata V. ${ }^{1}$

Hablar sobre el tema evaluación del aprendizaje en educación es un proceso algo complejo ya que, en este caso, muchos profesores manifiestan su insuficiente conocimiento para cumplir adecuadamente esta tarea debido a su incompleta preparación como docentes. Tenemos que reconocer que hoy día muchos profesores ejercemos la docencia sin estar debidamente preparados para desarrollarla debido a que hemos caído como paracaídas en esta importante labor.

Sin embargo, como afirma Manzi (2003), la evaluación es una oportunidad para analizar la calidad y eficacia del proceso enseñanzaaprendizaje ya producido y no podemos hacernos de la vista gorda para evitar la discusión de este tema. Además, se debe aclarar que el término evaluación se emplea muchas veces en forma intercambiable con el de medición, pero ambos términos no son sinónimos. La medición es un proceso más acotado y restringido, que se refiere al proceso de asignar números a cualidades observables o inobservables de los objetos de interés (ésta es parte de la evaluación), mientras que la evaluación es un proceso más integrativo acerca de las mismas cualidades del objeto de interés. En este caso, según Manzi (2003) estamos hablando de una evaluación de procesos o resultados, la cual normalmente tiene como propósito apreciar el nivel de logro de los objetivos formulados (función disgnóstica y de retroalimentación).
Con frecuencia, es común encontrar que muchos profesores intentamos explicar los problemas existentes en la evaluación del aprendizaje aludiendo a que la escala numérica que se utiliza para otorgar las notas a los estudiantes es una escala incompleta, inadecuada o injusta (v.g., a mí personalmente me resulta difícil asignarles $\mathrm{B}$ a dos estudiantes cuyas calificaciones son 81 y 88), planteando también la falta de objetividad en el proceso evaluativo. Entonces, nos preocupamos solamente por la confección de los exámenes, de sus preguntas, sin analizar otros aspectos más importantes relacionados con la objetividad de la evaluación tales como la planificación de los criterios que deben ser tomados en cuenta, sus indicadores, la coordinación con otros colegas, etc. Así, el otorgamiento de una calificación cuantitativa se convierte en la tarea más importante y a la vez más engorrosa para nosotros los profesores. En este sentido, predomina la concepción cuantitativa de la evaluación según la práctica que se ejecuta a pesar de que los profesores reconocen cognoscitivamente la importancia de una evaluación más cualitativa e integral del educando.

En mi experiencia personal, muchas veces me encuentro con casos de estudiantes que participan activamente en las clases, haciendo aportes importantes en la discusión de algún tópico pero que a la hora de un examen no son capaces de demostrar dominio de esos mismos temas en los cuales ellos han participado. Sin embargo, generalmente la forma

1 Licenciado en Educación: Física - Matemática, Pontificia Universidad Católica Madre y Maestra (PUCMM) de Santiago, Rep. Dom. Maestría en Educación Matemática, The University o British Columbia, de Vancouver, Canada. Coordinador del Area de Matemática del Consorcio de Evaluación e Investigación Educativa en la PUCMM. Profesor Tiempo Completo de Matemáticas Universitarias, Cálculo y Estadísticas, y Asesorías Metodológicas de Tesis de Administración, Mercadeo y Psicología. Pertenece al Departamento de Ciencias Básicas. Facultad de Ciencias y Humanidades de la PUCMM. jzapata@pucmmsti.edu.do 
de evaluación más frecuentemente utilizada es la de tipo sumativa o de cierre aún en las situaciones evaluativas frecuentes, no tendemos a practicar la diagnóstica ni la formativa; no orientamos al estudiante suficientemente sobre su aprendizaje de modo integral y priorizamos la información sobre su rendimiento cuantitativo fundamentalmente. Básicamente se evalúa para rendir resultados expresados cuantitativamente (calificación) y no para orientar el aprendizaje del alumno tanto cognitivo como metacognitivo con elementos que realmente puedan contribuir a su mejoramiento. La calificación de los resultados del aprendizaje cuantitativamente adquieren la mayor relevancia y se convierten en el sentido de la evaluación. Es decir, la nota es la información más apreciada por el estudiante que subordina cualquier otra información cualitativa sobre el aprendizaje.

Al valorar las fuentes principales para evaluar el aprendizaje del estudiante, las mismas se reducen fundamentalmente al tipo de examen oral o escrito en los cuales predominan preguntas reproductivas del conocimiento que tienen como fin esencial el de comprobar y calificar cuantitativamente el aprendizaje del estudiante. Las fuentes evaluativas se planifican (como el caso del examen) más para las evaluaciones sumativas y no tanto para las evaluaciones diagnósticas o formativas que resultan menos estructuradas sin que respondan a criterios establecidos previamente que orienten al profesor y al estudiante en la evaluación.

Para mí, la evaluación resulta en un buen espejo donde mirary mirarnos como docentes, donde se muestran las mayores debilidades pedagógicas, donde podemos descubrir el alma de este proceso. En ese sentido, aunque en la Universidad no tenemos muchas oportunidades de aplicar una evaluación integral, busco que la evaluación me retroalimente sobre la calidad alcanzada y me permita propiciar el carácter cualitativo y educativo de la misma, en un ambiente participativo y democrático, porque es un elemento esencial del proceso de enseñanza-aprendizaje que debe aplicarse tanto al aprendizaje de los alumnos como a la revisión de la propia práctica docente. Así que, en lo personal, procuro tomar en cuenta varios aspectos del proceso tales como:

1) Seleccionar y secuenciar los contenidos (conocimientos, procedimientos y actitudes) de mi programación de aula con una distribución y una progresión adecuadas a las características de cada grupo de alumnos.

2) Adoptar estrategias y programar actividades en función de los objetivos didácticos, de los distintos tipos de contenidos y de las características de los alumnos.

3) Planificar mi actividad educativa de forma coordinada con el resto del profesorado.

4) Plantear situaciones introductorias previas al tema que se va a tratar (diálogos, lecturas, etc.).

5) Mantener el interés del alumnado partiendo de sus experiencias, con un lenguaje claro y adaptado, dando ánimo y asegurando la participación de todos.

6) Facilitar la adquisición de nuevos contenidos a través de los pasos necesarios, intercalando preguntas aclaratorias, ejemplificando y sintetizando.

7) Comprobar que los alumnos han comprendido la tarea que tienen que realizar: haciendo preguntas, haciendo que verbalicen el proceso, etc.

8) Fomentar el respeto y la colaboración entre los alumnos y aceptar sus sugerencias y aportaciones, asegurándome de que las relaciones que establezco con ellos dentro del aula y las que éstos esta- 
blecen entre sí son correctas, fluidas y desde unas perspectivas no discriminatorias.

9) Favorecer la elaboración de normas de convivencia con la aportación de todos y reaccionando de forma ecuánime ante situaciones conflictivas.

Con respecto a los exámenes quiero puntualizar que, pensando en mis alumnos, siempre trato de:

- Distribuir exámenes parciales y un examen final en la asignatura durante el semestre.

- Utilizar exámenes escritos con diferentes variantes, que permitan constatar el desarrollo alcanzado por los estudiantes respecto a su aprendizaje.

- Utilizar varios formatos de un mismo examen parcial o final para un grupo (para así desmotivar el interés de cometer fraude $y$, más bien, fomentar la honestidad y confianza en su capacidad).

- Establecer la clave de calificación del examen, discutida con los estudiantes y autoevaluada y coevaluada por los mismos.

- Discutir los resultados de los exámenes con los estudiantes.

Finalmente, deseo señalar que la evaluación consiste en un proceso continuo que nos permite recoger sistemáticamente información relevante, con el objetivo de reajustar la intervención educativa de acuerdo con los aprendizajes reales del alumno. Así que cuando evaluamos los aprendizajes que han realizado nuestros alumnos, también estamos evaluando, se quiera o no, la enseñanza que hemos llevado a cabo. Con la evaluación tenemos la oportunidad de verificar la adecuación del proceso de enseñanza a las características y necesidades educativas del alumnado y, en función de ello, introducir las mejoras necesarias en la actuación docente con un carácter continuo y formativo.

Estas líneas de reflexión humildemente las comparto con el objetivo de que, a pesar de que nos desenvolvemos con algunas limitaciones importantes (sobre todo por el elemento tiempo), cada día podemos mejorar nuestra práctica educativa si estamos conscientes de algunos aspectos importantes como es el caso de la evaluación. Pues como afirma Sainz Leyva (2004), la evaluación del aprendizaje constituye una importante función que todo profesor debe saber realizar como parte de su actividad docente.

\section{Referencias:}

Manzi, Jorge (2003). Medición y Evaluación en Educación. En R. Hevia (Ed.). La Educación en Chile, Hoy. Santiago, Ediciones Universidad Diego Portales.

Sainz Leyva, Lourdes (2004). Apuntes y Reflexiones en torno a los Problemas de la Evaluación del Aprendizaje. En: www.nuestraldea.com/aseycap/12.htm 